\title{
Safety of anti-TNF therapy: 10 year experience in pediatric patients from a single tertiary center
}

\author{
G Espada*, SM Meiorin, L Guerini, M Alvarez, Giupponi \\ From 18th Pediatric Rheumatology European Society (PReS) Congress \\ Bruges, Belgium. 14-18 September 2011
}

\section{Background}

Anti-TNF agents are frequently used in the treatment of severe rheumatic disorders in childhood mainly Juvenile Idiopathic arthritis. Despite good clinical efficacy of this therapy, practitioners must remain alert for potential side effects, particularly after prolonged use (infections, malignancy and autoinmune events) .

\section{Objective}

Anti-TNF (Etanercept, infliximad and adalimumab) related adverse events were consecutively recorded and analized in pediatric patients with rheumatic disorders followed in our section from 2000 to 2010 .

\section{Methods}

Time of exposure, dose and reason for discontinuation were recorded Analysis involved incidence rate, outcome, and causal relationship. Statiscal analysis were performed using SPSS software.

Table

\begin{tabular}{llll}
\hline & Etanercept & Infliximab & Adalimumab \\
\hline Number of treatments & 105 & 43 & 12 \\
Mean age at onset,ys (SD) & $11.2(4.8)$ & $12.5(4.1)$ & $16.4(3.8)$ \\
Exposure time (pts-year) & 246,5 & 82,7 & 9,2 \\
Adverse events & 75 & 76 & 5 \\
Incidente rate AE & 0.3 & 0.9 & 0.5 \\
SAE (incidente rate) & $2(0.008)$ & $5(0.06)$ & $0(0)$ \\
Opportunistic infections & 1 & 2 & 0 \\
(Tuberculosis) & & & \\
Discontinuation due to AE n (\%) & $5(4.8)$ & $13(30.2)$ & 0 \\
\hline
\end{tabular}

\section{Results}

Data from 131 clinical records were analyzed . 87(66.4\%) were female, median age at diagnosis 7.2 (RIQ 3.8-11.3), median follow up 7.9 ys $(\mathrm{SD} \pm 4.8) .111$ pts had JIA, 5 JDM ,4 vasculitis, 3 sarcoidosis, 2MCTD,1SLE and 5 idiopathic uveitis.

Most of the AEs were mild: 28,2\% and 13,5 upper respiratory and skin infections respectively.

Four pts developed autoinmune events: Lupus -like syndrome, Psoriasis and 2 other ,optic neuritis .One pt under IFX + MTX developed Non-Hodgkin Limphoma and another on IFX fatal fulminant hepatitis.

\section{Conclusions}

In our series we observed a total of 156 AEs with incidence rates of: $0.3,0.5$ and 0.9 with Etanercept,adalimumab and infliximab respectively.

Seven pts developed SAEs including opportunistic infections (TB), serious infusion reactions, NHL and fulminant hepatitis. Eigtheen pts $(13,8 \%)$ discontinued antiTNF therapy due adverse events.

Published: 14 September 2011

doi:10.1186/1546-0096-9-S1-P68

Cite this article as: Espada et al: Safety of anti-TNF therapy: 10 year experience in pediatric patients from a single tertiary center. Pediatric Rheumatology 2011 9(Suppl 1):P68. 